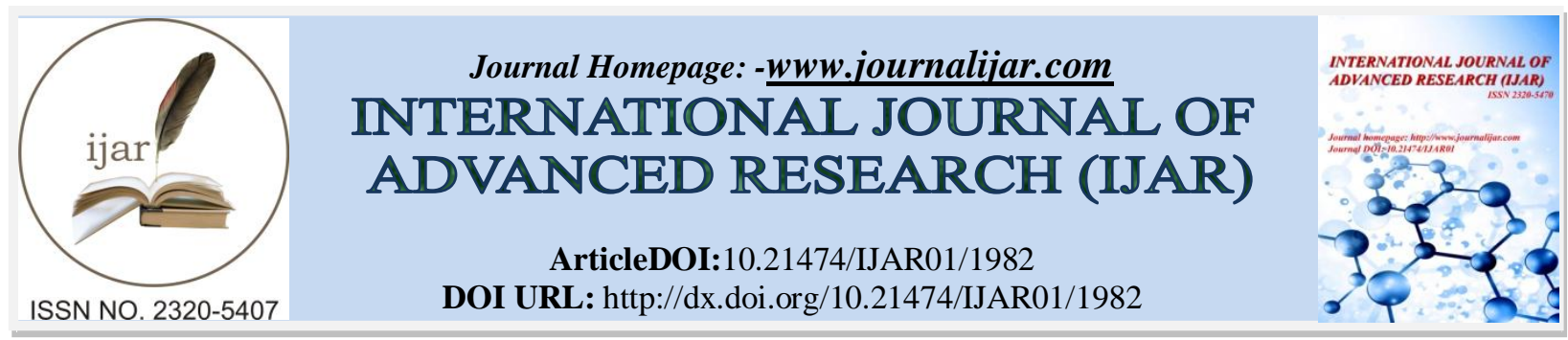

RESEARCH ARTICLE

\title{
NEUROLOGICAL COMPLICATIONS AMONG PEDIATRIC POSTLIVER TRANSPLANT IN KING ABDULAZIZ MEDICAL CITY-RIYADH.
}

\author{
Alanoud Al-Marzoug ${ }^{1}$, Hala Al-Marzoug ${ }^{1}$, Ahmed Al-Rumayyan ${ }^{2}$ and Abdullah Al-Zaben ${ }^{3}$. \\ 1. College of Medicine, King Saud bin Abdulaziz University for Health Sciences, Riyadh. \\ 2. Consultant Pediatric Neurology, King Abdullah Specialized Children's Hospital, Riyadh. \\ 3. Chairman of pediatric department, Consultant Pediatric Gastroenterology, King Abdullah Specialized \\ Children's Hospital, Riyadh.
}

\section{Manuscript Info}

(..........................

Manuscript History

Received: 12 August 2016

Final Accepted: 22 September 2016

Published: October 2016

Key words:-

Liver transplantation, Seizures, Pediatric

Liver transplant, Post operative

complications.

\section{Abstract}

Background:-Liver transplantation (LT) is an effective treatment for children with liver disease. ${ }^{1}$ Post-operative Neurological complications (NCs) are common among LT recipients. ${ }^{3}$ The aim of this study is to identify the NCs as well as determine the predictors of these complications among pediatric post LT in King Abdulaziz Medical City - Riyadh.

Methods:-Case-control study was conducted on 54 pediatric patients who had LT aged $\leq 14$ years old. Charts were reviewed from 2001 to 2014. Patients who had NCs post LT were identified as cases $n=12$ and who did not have NCs post LT were identified as controls $\mathrm{n}=42$. Analysis was conducted using SAS version 9.2.

Results:-The mean patients' age at the time of LT was (4.42 \pm 0.52$)$ year. Females were $28(51.85 \%)$ \& males were $26(48.15 \%)$. The most common indication of LT was PFIC followed by biliary atresia. NCs after LT was seen in 12 patients, 4(33.33\%) of them had neurological manifestations before LT. All patients who underwent LT were jaundiced 54(100\%). There was significant difference between cases/controls in pre-LT hepatic encephalopathy $\mathrm{p}=0.008$ and pre-LT neurological manifestations $\mathrm{p}=0.017$. The most common NC post LT was seizures $9(52.94 \%)$ followed by encephalopathy $4(23.53 \%)$ \& weakness $4(23.53 \%)$. There was significant difference between the two groups in pre and post-transplant INR $\mathrm{p}=0.003 \& \mathrm{p}=0.015$ respectively. None of the associated risk factors (patient's age, gender, post-op Mg) were significant predictors for developing NCs after LT. Conclusion:-NCs are common among children after LT. Early detection and management are of extreme importance.

Copy Right, IJAR, 2016,. All rights reserved.

\section{Introduction:-}

Liver transplantation (LT) is an effective increasingly and widely accepted treatment for children with liver disease. (Busuttil, 2005) In just two decades pediatric LT changed from being a clinical therapy practiced in only few centers in the United States and Western Europe to one that is performed worldwide in innumerable medical institutions. 
(Busuttil, 2005) The rationale behind liver transplantation is to improve the life expectancy and quality of life of the liver recipient, by restoring normal liver function.

The major indication for LT in infants and children is Hepatic failure, whether it is acute or the result of end-stage liver disease. The most frequent single disease indication in all series is Progressive biliary cirrhosis caused by biliary atresia. Other common indications are parenchymal liver diseases, including autoimmune and chronic viral hepatitis, certain metabolic diseases that lead to liver failure, and fulminant hepatic failure (FHF). It has been estimated in one of the studies for 500 pediatric LT recipients that the major indication for LT is hepatic failure with a rate of $95 \%$ followed by biliary atresia $62 \%$. (Busuttil, 2005)

The Saudi Center for Organ Transplantation, through its scientific committees has reported indications in which a liver transplant should be performed. The first indication is fulminant hepatic failure resulting from viral hepatitis such as, A, B, C, D, EBV and CM, metabolic liver disease, Wilson's disease. Secondly, advanced chronic liver diseases such as: primary biliary cirrhosis, biliary atresia, chronic viral hepatitis. Third, inherited metabolic disorders such as, Wilson's disease, Crigler-Najjar syndrome and fourth, localized liver tumors. (Saudi Center for Organ Transplantation, 2013)

Liver transplantation procedure is a high-risk procedure, carrying a significant risk for mortality under the best of circumstances. There is also potential for chronic disability and the requirement for long-term drug administration. (Busuttil, 2005) Post-transplant Neurological Complications (NCs) are common among LT recipients. (Vizzini et al., 2011) Among solid organ transplant recipients, LT recipients have the highest incidence of NCs. (Vizzini et al., 2011)The presence of Central nervous system (CNS) post-operative complications is associated with increased morbidity and mortality impacting the recipient's survival, recovery and quality of life. (Bemeur et al., 2013; Colombari et al., 2013) Compared with adults, complications in children are more severe and are significantly associated with greater mortality. (Donmez et al., 2009) The development of specialized transplantation centers, improvement of patient selection, and refinement of immune-suppression are recent advances that have improved patient survival, but complications still occur. (Donmez et al., 2009) Although not inevitable, some complications still arise in most cases. These complications can be secondary to the transplantation procedure itself or the underlying chronic disease. (Donmez et al., 2009)

One of the studies that were conducted in Saudi Arabia reported significant NCs after LT in 41 consecutive patients who had 45 procedures including: Encephalopathy, intermittent confusion and agitation, focal and generalized seizures, multifocal myoclonus, status epilepticus, and unclassified seizures. All patients with different types of seizures had encephalopathy. These complications have high mortality rate. Of 12 patients who died before discharge, 11 had encephalopathy post-transplant. (Ghaus et al., 2001)Another study that was done in Ohio, United States during a period of 30 years (1980-2010), reported out of 65 pediatric patients who underwent LT, 20 of them (30.7\%) had NCs. Seizures were the most common NC (16.9\%) followed by encephalopathy (7.6\%) and headache (6.1\%). (Ghosh et al., 2012)

Neurological complications post liver transplantation led to longer hospital stays with greater early morbidity and mortality. (Colombari et al., 2013)The incidence of these complications varies widely between studies and is generally reported to occur in 19\% - 90\% of LT recipients. (Donmez et al., 2009) Due to these high rates, knowledge of these potential neurological events and their significantly associated factors appears to be extremely important for the multidisciplinary transplantation team to decrease these complications' prevalence as well as to diagnose and treat them early. (Colombari et al., 2013) To date, only few studies have specifically investigated neurological complications post liver transplantation, particularly among pediatric age group. (Ghosh et al., 2012) The aim of this study is to identify the neurological complications among pediatric post liver transplantation as well as to determine the risk and predictive factors in King Abdulaziz Medical City - Riyadh.

\section{Methodology:-}

This study was approved by King Abdullah International Medical Research Center (KAIMRC) and the Institutional Review Board (IRB). All pediatric LT recipients (age $\leq 14$ years at the time of the transplant) who received liver transplants at King Abdulaziz Medical City in Riyadh and were maintained in the pediatric transplant database during the period of 13 years (2001-2014) were included in the analysis. The charts of patients satisfying the following inclusion criteria were analyzed in more detail. 


\section{Inclusion criteria:-}

The inclusion criteria were children aged $\leq 14$ years at the time of LT and neurological complications after LT. The charts were reviewed retrospectively and the following data were recorded: demographics of the recipient and the donor including age and gender, indication for LT, pre and post-transplant data (neurological manifestations, hepatic encephalopathy, ascites, jaundice, total serum bilirubin, serum magnesium, serum sodium, serum calcium, International Normalized Ratio (INR), serum creatinine and total Albumin). Lab data were recorded 24 hours before and after LT. Neurological complications were defined based on neurological history and examination. Clinical examinations were done by physicians from pediatric intensivists, gastroenterologists, transplant surgeons, and pediatric neurologists who confirmed the neurological findings.

\section{Statistical analyses:-}

This study was a case-control study. A total of 54 pediatric patients were included in the analysis. Patients who had neurological complications after LT were identified as cases $(n=12)$ and those who did not have neurological complications after LT were identified as controls $(\mathrm{n}=42$ ). All analysis was conducted using SAS version 9.2 (SAS Institute Inc., Cary, NC).Categorical variables such as (gender, indication of liver transplant, hepatic encephalopathy, pre-transplant neurological manifestations, ascites, and jaundice)were compared between study groups (caseslcontrols) by utilizing chi-square and equivalent non-parametric test. The results were reported in terms of count, percent and corresponding p-values. Continuous variables such as patients' age, donors' age, pre and posttransplant lab data including (total serum bilirubin, serum magnesium, serum sodium, serum calcium, INR, total albumin) were compared between study groups by utilizing t-test. The results were reported in terms of mean and corresponding p-values. Logistic regression was utilized to identify the predictors of neurological complications among children who had liver transplantation. Forthisanalysis, the dependent variable was a binary variable (cases vs. controls) indicating whether any given participant has developed neurological complications or not. The independent variables included:patients' age, patients' gender and post-operative serum magnesium. The results of the model were reported in terms of OR, 95\% C.I and p-value. Significance was declared at p-value less than 0.05 .

\section{Results:-}

Of 54 pediatric patients who underwent LT, 12 patients developed neurological complications post-transplant and 42 did not develop any neurological complications. The mean patients' age at the time of transplantation was $(4.42 \pm$ $0.52)$ year. There were $28(51.85 \%)$ females, of whom 5 (41.67\%) developed neurological complications. Whereas males were $26(48.15 \%)$, of whom 7(58.33\%) developed neurological complications. The mean donors' age was $23.75 \pm 1.58$ year with males being more than females $40(74.07 \%)$ and $14(25.93 \%)$, respectively (Table 1$)$. The most common cause of liver failure necessitating liver transplant in our study was Progressive Familial Intrahepatic Cholestasis (PFIC) followed by biliary atresia. PIFC was diagnosed in $20(37.04 \%)$ patients while biliary atresia was diagnosed in 12(22.22\%) patients (Table 2).

Nervous system manifestations before LT were present in only 6(11.11\%) patients which include peripheral neuropathy, epilepsy, ataxic gait and slurred speech, seizure, hallucination, delirium and somnolence. Of the 12 patients who developed NCs post-transplant; their clinical characteristics prior to the transplant were as follows: all of them were jaundiced 12(100\%), 4(33.33\%) patients had nervous system manifestations, 7(58.33\%) patients had ascites, 3(5.56\%) patients had hepatic encephalopathy. Of the 42 patients who did not develop any NCs after LT; their clinical characteristics prior to the transplant were as follows: all of them were jaundiced $42(100 \%), 2(4.76 \%)$ patients had nervous system manifestations, 24(58.54\%) patients had ascites and none of this group had hepatic encephalopathy (Table 1).

Pre-operative lab data showed that the mean value for pre-transplant INR was $(3.16 \pm 0.87)$ for the cases and $(1.61 \pm$ 0.10 ) for the controls (Table 1). Meanwhile the post-operative lab data showed that the mean post-transplant INR in the cases was $(3.53 \pm 1.14)$ which was higher than the control group $(1.91 \pm 0.09)$. The mean value for posttransplant $\mathrm{Na}$ was within normal range in both groups(normal range 136-145) (Table 3).

The neurological complications following LT are summarized in (Table 4). The most common neurological complication post LT was seizures $9(52.94 \%)$ followed by encephalopathy $4(23.53 \%)$ and weakness $4(23.53 \%)$. Of all patients who underwent liver transplant, only five patients died, 4 of them had post-transplant neurological complications which has nothing to do with the mortality. 
The risk factors for developing post-transplant neurological complications among children were analyzed by the logistic regression analysis. Our data showed that the odds ratio (OR) for patient's age was 0.97 (0.81-1.15, 95\% CI), Patient's gender (female vs male) OR $0.50(0.13-1.89,95 \% \mathrm{CI})$, post-operative serum magnesium (abnormal vs normal) OR $0.30(0.03-2.68,95 \%$ CI $)$ (Table 5).

\section{Discussion:-}

To date, only few studies in Saudi Arabia have looked at the neurological complications in pediatric age group after LT. The incidence of these complications varies widely between studies and generally reported to be in multiple studies from $8 \%$ to $46 \%$ range, while in other studies it was from 19-90\%. In our series of 54 patients, $12(22.2 \%)$ developed NCs, which is within the range of previously reported rates in the published literature.(Donmez et al., 2009; Menegaux et al., 1994; Choi et al, 2004; Erol et al., 2007; Gridelli et al., 1994; Garg et al., 1993) Seizure is the most common neurological complication in our study which is in line with the previously published studies. We reported seizures in 9 (52.94\%) patients out of 12 who developed post-transplant NCs, that is comparable to Garg et al's study who reported seizures in 9 of 11 pediatric patients after LT. (Garg et al., 1993)It is reported in the literature that seizures usually occur in $0-40 \%$ of LT recipients with a potential decrease in numbers over time in the more recent reports. Seizures most often occur early after surgery and the main etiology is attributed to immunosuppressant's toxicity. Furthermore, seizures developed post-transplant due to several factors e.g. hypoxicischemic injury, drugs, sudden withdrawal of narcotic agents, or abrupt discontinuation of anticonvulsant drugs in epileptic patients, acute metabolic derangement, and cerebral lesions. (Gilhus et al., 2010) In our study, we identified hypoxic-ischemic injury as the cause of seizure in two patients and one patient was already epileptic prior to LT and continue to show seizure after transplant. The cause of seizure was not identified in the rest of the patients, however, we think that immunosuppressant's toxicity has a role in the development of seizure in these patients.

The second most common neurological complicationsin our series after seizures are encephalopathy and weakness. Encephalopathy has been reported in the literature in $15 \%$ to $33 \%$ of pediatric LT recipients which is comparable with our results (23.53\%). (Ghosh et al., 2012) We defined encephalopathy when the patient experienced any level of mental status changes in the form of lethargy, headache, stupor or had non focal neurological findings. We defined weakness when the patient had focal or generalized type of weakness including myopathy and peripheral neuropathy. Focal weakness is generally reported with an incidence of 2-13\% for mono-neuropathies and 1-5.8\% for brachial plexopathy. Generalized weakness is mainly related to critical illnesses and immunosuppression neurotoxicity and reported in the literature with an incidence of 1.5-10\%. (Gilhus et al., 2010) In our series, weakness represented $23.53 \%$ which is higher than the reported numbers in the literature.

Nervous system manifestations before LT showed statistically significant difference between the study groups (caseslcontrols) ( $\mathrm{p}=0.017)$. These were noted in 6 patients, 4 of them had post-transplant neurological complication. Pre-operative hepatic encephalopathy also showed statistically significant difference between the two study groups $(\mathrm{p}=0.008)$. It was present in 3 patients who also continue to show neurological complications after the transplant. These NCs after LT could be attributable to the presence of nervous system manifestations prior to the transplant.

Risk factors such as: patients' age, patents' gender, post-operative serum Mg in our study did not achieve statistical significance for the prediction of NCs after LT. The logistic model is a weak model (c-statistics $=0.660)$ and this is explained by the small population size. In the analysis, we did not include post LTserum Na or serum Ca because they all showed one level values (i.e. all patients had normal post LT serum Na and had abnormal post LT serum $\mathrm{Ca}$ ). Ghaus et al's study reported that hypomagnesemia after LT was a significant predictor and associated with the development of nervous system complications, however, the underlying mechanism has not been clearly established. (Gilhus et al., 2010) More interestingly, it is not known whether the outcome in these patients would be changed or affected if the hypomagnesemia was corrected. Studying these factors is an area for future research.

There was no significant difference between the two groups in regards to pre-transplant lab data except for pretransplant INR ( $\mathrm{p}=0.003$ ) as shown in (Table 1). Post-transplant lab data showed significant difference between the two groups in post-transplantINR with a p-value of (0.015) (Table 4). There was no significant difference between the two groups in regards to the remaining post-transplant lab data. We did not find explanation for the abnormal values of INR before and after LT, further studies are needed to evaluate the association between INR and NCs after LT. 
The main limitation of this study is the small population size limiting the ability of investigating more variables to determine the predictors and risk factors of developing NCs after LT. Another limitation of the study is its retrospective design. There is a possibility that some of the neurological complications were not documented in the charts leading to underestimation of some findings.

Table 1: Demographic, and Pre-Operative Clinical Characteristics of the Study Groups

\begin{tabular}{|c|c|c|c|c|}
\hline Variables & $\begin{array}{l}\text { Overall } \\
(n=54)\end{array}$ & \begin{tabular}{|l|} 
Neurological \\
Complications \\
Yes $(\mathrm{n}=12)$ \\
\end{tabular} & $\begin{array}{l}\text { Neurological } \\
\text { Complications } \\
\text { No }(n=42)\end{array}$ & p-value \\
\hline Patient' Age (mean \pm SE) & $4.42 \pm 0.52$ & $4.30 \pm 1.18$ & $4.45 \pm 0.59$ & $0.904^{\wedge}$ \\
\hline \multicolumn{5}{|l|}{ Patients gender $\mathrm{n}(\%)$} \\
\hline Male & $26(48.15)$ & $7(58.33)$ & 19(45.24) & \multirow[t]{2}{*}{$0.423 *$} \\
\hline Female & $28(51.85)$ & $5(41.67)$ & $23(54.76)$ & \\
\hline Donor's Age (mean \pm SE) & $23.75 \pm 1.58$ & $19.97 \pm 3.35$ & $24.83 \pm 1.77$ & $0.202^{\wedge}$ \\
\hline \multicolumn{5}{|l|}{ Donor's gender $\mathrm{n}(\%)$} \\
\hline Male & $40(74.07)$ & 11(91.67) & $29(69.05)$ & \multirow[t]{2}{*}{$0.151 * *$} \\
\hline Female & $14(25.93)$ & $1(8.33)$ & $13(30.95)$ & \\
\hline \multicolumn{5}{|l|}{ Pre-operative Data } \\
\hline \multicolumn{5}{|l|}{ Ascites $\mathrm{n}(\%)$} \\
\hline Yes & $31(58.49)$ & $7(58.33)$ & $24(58.54)$ & \multirow[t]{2}{*}{$1.00 * *$} \\
\hline No & $22(41.51)$ & $5(41.67)$ & $17(41.46)$ & \\
\hline \multicolumn{5}{|l|}{ Jaundice $\mathrm{n}(\%)$} \\
\hline Yes & $54(100)$ & $12(100)$ & $42(100)$ & - \\
\hline \multicolumn{5}{|c|}{ Pre-operative hepatic encephalopathy $\mathrm{n}(\%)$} \\
\hline Yes & $3(5.56)$ & $3(25.0)$ & 0 & \multirow[t]{2}{*}{$0.008^{* *}$} \\
\hline No & $51(94.44)$ & $9(75.0)$ & $42(100)$ & \\
\hline \multicolumn{5}{|c|}{ Pre-operative neurological manifestations n(\%) } \\
\hline Yes & $6(11.11)$ & $4(33.33)$ & $2(4.76)$ & \multirow[t]{2}{*}{$0.017 * *$} \\
\hline No & $48(88.89)$ & $8(66.67)$ & $40(95.24)$ & \\
\hline $\begin{array}{l}\text { Pre-operative Bilirubin(mean } \\
\pm \text { SE) }\end{array}$ & $296.88 \pm 28.53$ & $337.65 \pm 47.81$ & $283.29 \pm 34.69$ & $0.415^{\wedge}$ \\
\hline $\begin{array}{l}\text { Pre-operative } \mathrm{Na} \\
(\text { mean } \pm \mathrm{SE})\end{array}$ & $136.22 \pm 0.48$ & $136.75 \pm 0.96$ & $136.05 \pm 0.56$ & $0.541^{\wedge}$ \\
\hline $\begin{array}{l}\text { Pre-operative INR (mean } \pm \\
\text { SE) }\end{array}$ & $1.98 \pm 0.24$ & $3.16 \pm 0.87$ & $1.61 \pm 0.10$ & $0.003^{\wedge}$ \\
\hline $\begin{array}{l}\text { Pre-operative } \mathrm{Ca} \\
(\text { mean } \pm \mathrm{SE})\end{array}$ & $2.24 \pm 0.04$ & $2.21 \pm 0.06$ & $2.25 \pm 0.05$ & $0.644^{\wedge}$ \\
\hline $\begin{array}{l}\text { Pre-operative } \mathrm{Mg} \\
(\text { mean } \pm \mathrm{SE})\end{array}$ & $0.84 \pm 0.02$ & $0.85 \pm 0.05$ & $0.84 \pm 0.02$ & $0.720^{\wedge}$ \\
\hline $\begin{array}{l}\text { Pre-operative Total } \\
\text { Albumin }(\text { mean } \pm \text { SE) }\end{array}$ & $34.0 \pm 1.18$ & $21.25 \pm 2.37$ & $34.89 \pm 1.35$ & $0.188^{\wedge}$ \\
\hline $\begin{array}{l}\text { Pre-op serum creatinine(mean } \\
\pm \text { SE) }\end{array}$ & $30.61 \pm 1.74$ & $25.87 \pm 2.95$ & $32.20 \pm 2.05$ & $0.115^{\wedge}$ \\
\hline
\end{tabular}


Table 2: Causes of Liver Failure Necessitating Liver Transplant

\begin{tabular}{|l|c|c|}
\hline \multicolumn{1}{|c|}{ Variables } & $\begin{array}{c}\text { Neurological Complications } \\
\text { Yes }(\mathrm{n}=12) \\
\mathrm{n}(\%)\end{array}$ & $\begin{array}{c}\text { Neurological Complications } \\
\text { No (n= 42) } \\
\mathrm{n}(\%)\end{array}$ \\
\hline $\begin{array}{l}\text { Progressive Familial Intrahepatic } \\
\text { Cholestasis (PFIC) }\end{array}$ & $3(25.0)$ & $17(40.48)$ \\
\hline Biliary atresia & $2(16.67)$ & $10(23.81)$ \\
\hline CrigglerNajjar Syndrome & $1(8.33)$ & $3(7.14)$ \\
\hline Wilsons disease & $1(8.33)$ & $4(9.52)$ \\
\hline Budd chiari syndrome & $1(8.33)$ & 0 \\
\hline Hepatoblastoma & 0 & $3(7.14)$ \\
\hline Alagille syndrome & $1(8.33)$ & $1(2.38)$ \\
\hline Cholestasis & $1(8.33)$ & $2(4.76)$ \\
\hline Tyrosinemia & 0 & $1(2.38)$ \\
\hline Acute Liver Failure & $2(16.67)$ & 0 \\
\hline Hepatitis C Virus & 0 & $1(2.38)$ \\
\hline
\end{tabular}

Table 3: Post-Operative Lab Data

\begin{tabular}{|l|l|l|l|l|}
\hline Variables & $\begin{array}{l}\text { Overall } \\
\mathrm{n}=54\end{array}$ & $\begin{array}{l}\text { Neurological } \\
\text { Complications } \\
\text { Yes (n=12) }\end{array}$ & $\begin{array}{l}\text { Neurological } \\
\text { Complications } \\
\text { No(n=42) }\end{array}$ & p-value* \\
\hline $\begin{array}{l}\text { Post-operative } \\
\text { Bilirubin } \\
\text { (mean } \pm \text { SE) }\end{array}$ & $145.80 \pm 13.34$ & $163.75 \pm 24.33$ & $140.74 \pm 15.72$ & 0.480 \\
\hline $\begin{array}{l}\text { Post-operative Na } \\
\text { (mean } \pm \text { SE) }\end{array}$ & $142.15 \pm 0.60$ & $144.58 \pm 1.36$ & $141.43 \pm 0.62$ & $\mathbf{0 . 0 2 3 ^ { * }}$ \\
\hline $\begin{array}{l}\text { Post-operative INR } \\
\text { (mean } \pm \text { SE) }\end{array}$ & $2.30 \pm 0.29$ & $3.53 \pm 1.14$ & $1.91 \pm 0.09$ & $\mathbf{0 . 0 1 5 ^ { * }}$ \\
\hline $\begin{array}{l}\text { Post-operative Ca } \\
\text { (mean } \pm \text { SE) }\end{array}$ & $1.94 \pm 0.04$ & $2.00 \pm 0.08$ & $1.92 \pm 0.04$ & 0.396 \\
\hline $\begin{array}{l}\text { Post-operative Mg } \\
\text { (mean } \pm \text { SE) }\end{array}$ & $0.79 \pm 0.02$ & $0.82 \pm 0.04$ & $0.78 \pm 0.03$ & 0.450 \\
\hline $\begin{array}{l}\text { Post-operative total } \\
\text { albumin } \\
\text { (mean } \pm \text { SE) }\end{array}$ & $25.84 \pm 0.86$ & $25.73 \pm 1.92$ & $25.87 \pm 0.97$ & 0.945 \\
\hline $\begin{array}{l}\text { Post-operative serum } \\
\text { creatinine (mean } \pm \\
\text { SE) }\end{array}$ & $29.27 \pm 1.78$ & $35.17 \pm 5.80$ & $27.50 \pm 1.47$ & 0.068 \\
\hline
\end{tabular}

*Significant

Table 4: Neurological Complications Post-Liver Transplant

\begin{tabular}{|c|c|}
\hline Variables & Statistics \\
\hline Seizures n(\%) & $9(52.94)$ \\
\hline Encephalopathy n(\%) & $4(23.53)$ \\
\hline Weakness n(\%) & $4(23.53)$ \\
\hline \multicolumn{2}{|c|}{ Sixth cranial nerve palsy, tremors } \\
\hline
\end{tabular}

*the table is reported for cases only

**the complications are multi-select (so don't add up-to $n=12$ (cases)) 
Table 5: Risk Factors of developing post-operative Neurological Complications among Children

\begin{tabular}{|c|c|c|c|}
\hline Variables & OR & $\begin{array}{c}\text { 95\% C.I } \\
\text { (lower-upper) }\end{array}$ & P-value \\
\hline Patient's Age & 0.97 & $0.81-1.15$ & 0.770 \\
\hline $\begin{array}{c}\text { Patient's gender } \\
\text { (female vs. male) }\end{array}$ & 0.50 & $0.13-1.89$ & 0.308 \\
\hline $\begin{array}{c}\text { Post-operative serum magnesium } \\
\text { (abnormal vs. normal) }\end{array}$ & 0.30 & $0.03-2.68$ & 0.281 \\
\hline
\end{tabular}

\section{Conclusion and Recommendations:-}

Neurological complications in pediatric age group are common after LT. It is of utmost importance for the multidisciplinary transplantation team to be aware of these potential neurological events and their significantly associated factors in order to ensure accurate diagnosis and to set an early appropriate management plan. The occurrence and types of neurological complications varied widely after LT, however seizures seem to be the predominant most common complication. We recommend establishing a multicenter study in our country that evaluate the NCs after LT considering our study as a baseline in order to have representative data and evaluate large sample size. Although the results of this study contribute to the body of the literature, further studies are needed to identify the underlying risk factors and predictors of NCs after LT.

\section{References:-}

1. Busuttil RW, Klintmalm GB. (2005): Transplantation of the Liver: Elsevier Saunders.

2. Liver Transplatation. Saudi Center for Organ Transplatation 2013 [cited 2013 Aug 1]; Available from: https://www.scot.org.sa/en/en/directory-of-regulations/liver-transplantation.html.

3. Vizzini G, Asaro M, Miraglia R, Gruttadauria S, Filì D, D'Antoni A, et al. (2011): Changing Picture of Central Nervous System Complications in Liver Transplant Recipients. Liver Transplantation., 17(11):1279-85.

4. Bemeur C. (2013): Neurological Complications Post-liver Transplantation: Impact of Nutritional Status. Metab Brain Dis., 28(2):293-300.

5. Colombari RC, de Ataíde EC, Udo EY, Falcão ALE, Martins LC, Boin IFSF. (2013): Neurological Complications Prevalence and Long-term Survival after Liver Transplantation. Transplantation Proceedings., 45(3):1126-9.

6. Donmez FY, Guvenc Z, Emiroglu FK, Coskun M, Haberal M. (2009): Evaluation of Neurological Complications in Pediatric Liver Transplant Recipients: MRI versus CT. J Child Neurol., 24(6):656-63.

7. Ghaus N, Bohlega S, Rezeig M. Neurological Complications in Liver Transplantation. (2001): J Neurol., 248(12):1042-8.

8. Ghosh P, Hupertz V, Ghosh D. (2012): Neurological Complications Following Pediatric Liver Transplant. JPGN., 54(4):540-6.

9. Menegaux F, Keeffe EB, Andrews BT, et al. (1994): Neurological Complications of Liver Transplantation in Adult versus Pediatric Patients. Transplantation., 58(4):447-50.

10. Choi EJ, Kang JK, Lee SA, et al. (2004): New-onset Seizures after Liver Transplantation: Clinical Implications and Prognosis in Survivors. Eur Neurol., 52(4):230-6.

11. Erol I, Alehan F, Ozcay F, et al. (2007): Neurological Complications of Liver Transplantation in Pediatric Patients: A Single Center Experience. Pediatr Transplant., 11(2):152-9.

12. Gridelli B, Lucianetti A, Rodriguez G, et al. (1994): Neurologic Complications following Pediatric Orthotopic Liver Transplantation. Transplant Proc., 26(1):193-4.

13. Garg BP, Walsh LE, Pescovitz MD, et al. (1993): Neurologic Complications of Pediatric Liver Transplantation. Pediatr Neurol., 9(6):444-8.

14. Gilhus, N. E., Barnes, M. P. and Brainin, M. (2010) Neurological problems in liver transplantation, in European Handbook of Neurological Management, Second Edition, Volume 1, Second Edition, Wiley-Blackwell, Oxford, UK. 